This item was submitted to Loughborough's Research Repository by the author.

Items in Figshare are protected by copyright, with all rights reserved, unless otherwise indicated.

\title{
Assessing change in access to WASH in Palestinian schools
}

PLEASE CITE THE PUBLISHED VERSION

https://doi.org/10.3362/1756-3488.18-00039

\section{PUBLISHER}

(C) Practical Action Publishing

\section{VERSION}

VoR (Version of Record)

\section{PUBLISHER STATEMENT}

This work is made available according to the conditions of the Creative Commons Attribution-NonCommercialNoDerivatives 4.0 International (CC BY-NC-ND 4.0) licence. Full details of this licence are available at: https://creativecommons.org/licenses/by-nc-nd/4.0/

\section{LICENCE}

CC BY-NC-ND 4.0

\section{REPOSITORY RECORD}

Von Medeazza, Gregor, Sue Cavill, and Julie Fisher. 2019. "Assessing Change in Access to WASH in Palestinian Schools". figshare. https://hdl.handle.net/2134/37363. 
Gregor von Medeazza (gvonmedeazza@unicef.org) is UNICEF deputy country representative for Namibia; Sue Cavill (suecavill@hotmail.com) is a freelance consultant; Julie Fisher (J.Fisher1@lboro.ac.uk) is a lecturer at the Water, Engineering and Development Centre, Loughborough University, UK

The paper is based on the 'Water, Sanitation and Hygiene in Schools: Knowledge, Attitudes and Practices Survey' which was funded by the Government of Australia (DFAT) and conducted by the Ministry of Education and Higher Education, the United Nations Children's Fund (UNICEF) office in the State of Palestine, and Alpha International, in 2015-2016. (C) Practical Action Publishing, 2019, www.practicalactionpublishing.org http://dx.doi.org/10.3362/1756-3488.18-00039, ISSN: 0262-8104 (print) 1756-3488 (online)

\section{[CH]Assessing change in access to WASH in Palestinian schools}

\section{[AU]GREGOR VON MEDEAZZA, SUE CAVILL, and JULIE FISHER}

[ABS]This paper presents the main results from a knowledge, attitudes, and practices (KAP) survey on water, sanitation, and hygiene (WASH) in government schools in the State of Palestine (SoP). In 2012 a baseline WASH KAP survey was conducted in 411 schools. In 2015-2016 a statistically representative survey was performed; the sample included 381 of the 411 schools originally sampled in 2012. The survey targeted basic and secondary schools in urban and rural areas of all educational directorates in the West Bank and Gaza. The survey was conducted by UNICEF in coordination with the Ministry of Education and Higher Education (MoEHE). The findings of the 2016 survey show positive changes in the availability of potable water in schools, which also enabled hygiene and sanitation activities to improve. For instance, more schools taught hygiene education to students on a daily basis in 2016 than in 2012. However, the survey revealed that ensuring the participation of parents and students in WASH activities and continuity of supply of soap, toilet paper, and sanitary pads remains a challenge. This paper concludes with recommendations to further improve the access to WASH in Palestinian schools.

[KEY]Keywords: Palestine, water, sanitation, hygiene, schools

SCHOOLS ARE A MAJOR DETERMINANT of children's well-being. Within schools, water, sanitation, and hygiene (WASH) facilities are essential in promoting health, as well as improving school attendance and performance (Trinies et al., 2016; Chard and Freeman, 2018; Garn et al., 2016). The Sustainable Development Goals refer to universal access to WASH and inclusive and effective learning environments for all: including access to basic drinking water; single-sex basic sanitation facilities; and basic handwashing facilities in schools.

Increasing access to WASH in schools can have a range of impacts including improving the health, attendance, and comfort of students and teachers (Alexander et al., 2016). In water-scarce areas, water supply improvements - together with school hygiene promotion, water treatment interventions, and school sanitation improvements - can reduce diarrhoeal diseases among children (Dreibelbis et al., 2014). A school-based WASH intervention in Mali also had a positive effect on reducing rates of illness as well as absence due to diarrhoea (Trinies et al., 2016). Improving school water supply can reduce the burden of neglected tropical diseases such as schistosomiasis (Grimes et al., 2016), worm infections (Freeman et al., 2016), and respiratory infections (Trinies et al., 2016).

Other studies have shown that schools with poor water access during the dry season that received an improved water supply also saw improvements in hygiene promotion, water treatment, and sanitation as well as increased enrolment and better gender parity within this (Garn et al., 2013). Hunter et al. (2015) found a strong association between free and safe drinking water and reduced absenteeism 
in the dry season in Laos, suggesting that improved hydration leads to a better school experience for children. In the West Bank and the Gaza Strip a positive relationship was found between educational level and attitudes and practice of washing hands before eating (Al-Khatib et al., 2015). Ghrayeb et al. (2015) found that prevalence of hand washing among Palestinian school adolescents was high compared with adolescents in other regional studies. Discrimination against Palestinian girls associated with menstrual hygiene is noted where sanitation in schools is inadequate, where there is no water, or waste bins for sanitary pads or a place to change privately, all of which lead to an interruption in the learning process (GVC, AICS, UN Women, Palestinian Water Authority, 2017).

One of the barriers to improving access to WASH in schools is the lack of data to provide evidence to policymakers and donors on coverage, outcomes, and impacts. UNICEF, in coordination with the Ministry of Education and Higher Education (MoEHE), conducted a knowledge, attitudes, and practices (KAP) survey in 2016 on WASH in government schools in the State of Palestine (SoP). This survey measured availability of WASH infrastructure in schools, as well as the provision of hygiene education activities and the participation of teachers, parents, and students in these. The survey assessed changes in knowledge, attitudes, and practices of students related to hygiene behaviour. This paper presents the findings of the study, comparing the results with those of a baseline KAP survey conducted in 2012 to inform a set of policy recommendations.

During the period between the baseline and 2016 KAP survey, UNICEF and MoEHE implemented a project called 'Improving WASH facilities in prioritized schools in the West Bank and Gaza Strip (2012-2014)', with financial support from AusAid. The overall goal of the project was to contribute to a safer and healthier learning environment in MoEHE schools in the West Bank and Gaza Strip through improving water and sanitation conditions and personal and public hygiene practices of students and teachers (both male and female). Agencies have also addressed Gaza's specific water problems (over-pumping and seawater intrusion). For instance, with EU funding UNICEF has built a seawater desalination plant and piloted solar distillation technology in schools.

\section{[A]Schools in the State of Palestine}

More than 1 million children in the State of Palestine are enrolled in a total of 2,856 schools (MoEHE, 2013). Schools are either separate for boys (36 per cent), for girls (33 per cent), or are co-educational (31 per cent). Approximately 73 per cent are run by the MoEHE as government schools, which are free and compulsory until grade 10. Schools run by the United Nations Relief and Works Agency (UNRWA) constitute approximately 12 per cent of the total, mainly servicing refugee camps, for students usually up to grade 9 only, as the secondary schools are run by the MoEHE. Finally, the private sector (forprofit and not-for-profit institutions) supervises approximately 14 per cent of all schools.

Basic education is divided into the preparatory stage (grades one to four, 6 to 10 years old) and the empowerment stage (grades five to ten, 10 to 16 years old). Secondary education includes grades 11 and 12 (16 to 18 years old), which can be academic or vocational. At the end of 12 years of schooling, students take the secondary school examination called the Tawjihi, achievement of which qualifies them for tertiary education.

\section{[B]Access to WASH in the State of Palestine}

Of the total population in the West Bank and Gaza Strip 60 per cent have safely managed sanitation and 88 per cent have basic drinking water (WHO/UNICEF, 2018). There are differences between rural and urban: 86 per cent of the urban population has at least basic drinking water supply, compared with 94 per cent of the rural population. In rural areas, almost all people have a basic sanitation facility (99 per cent of the population, the remaining 1 per cent defecate in the open), compared with 95 per cent of the urban population (where the remaining 5 per cent share facilities). Around 83 per cent of the population of Gaza buys drinking water from private vendors. The context places a number of limitations on the ability of authorities to achieve universal access for water and sanitation in SoP.

\section{[B]WASH in schools}

The Sustainable Development Goals (targets 4.a, 6.1, 6.2) recognize the importance of WASH in schools as key components of a 'safe, non-violent, inclusive and effective learning environment' and part of 'universal' WASH access. WHO and UNICEF are monitoring WASH in primary and 
SCHOOLS

secondary schools by tracking 'basic' drinking water, sanitation, and hygiene services under the Joint Monitoring Programme (JMP).

Globally, 69 per cent of schools had a basic drinking water service, 66 per cent of schools had a basic sanitation service, and 53 per cent of schools had a basic hygiene service in 2016

(WHO/UNICEF, 2018).

In the West Bank and Gaza Strip 80 per cent of schools, nationally, have a basic drinking water supply, 81 per cent have basic sanitation, and 23 per cent of schools have a basic level of hygiene (WHO/UNICEF, 2018) (see Figures 1-3). Schools in urban areas and primary schools are more likely to have a limited service for sanitation, drinking water, and hygiene. Elsewhere in the region of northern Africa and western Asia, 74 per cent of schools have access to a basic water supply in 2016, 82 per cent of schools have basic sanitation, and 71 per cent have a basic level of hygiene (WHO/UNICEF, 2018).

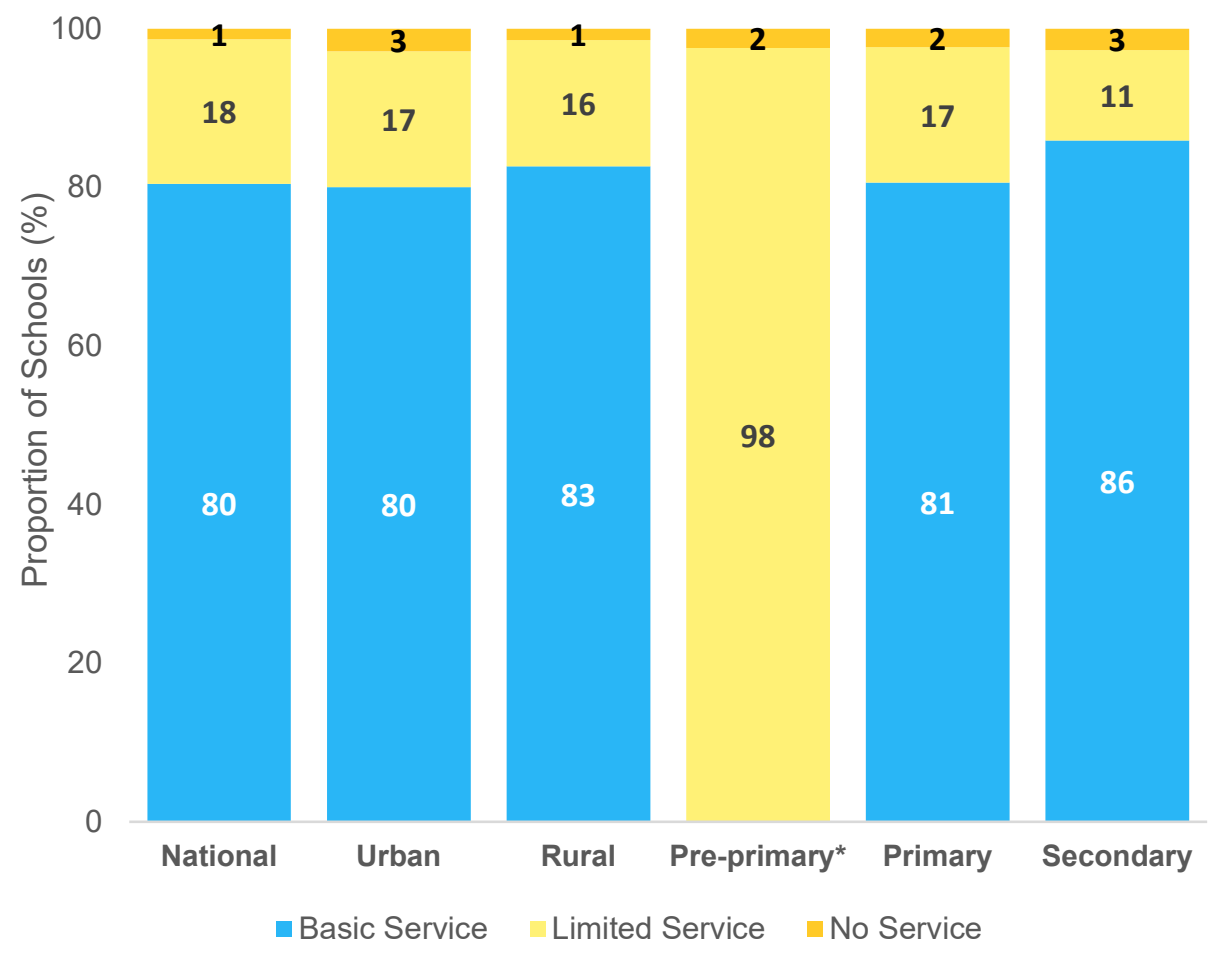

[CAP]Figure 1 Access to water in schools

[S]Source: Joint Monitoring Programme (2018) 


\section{SCHOOLS}

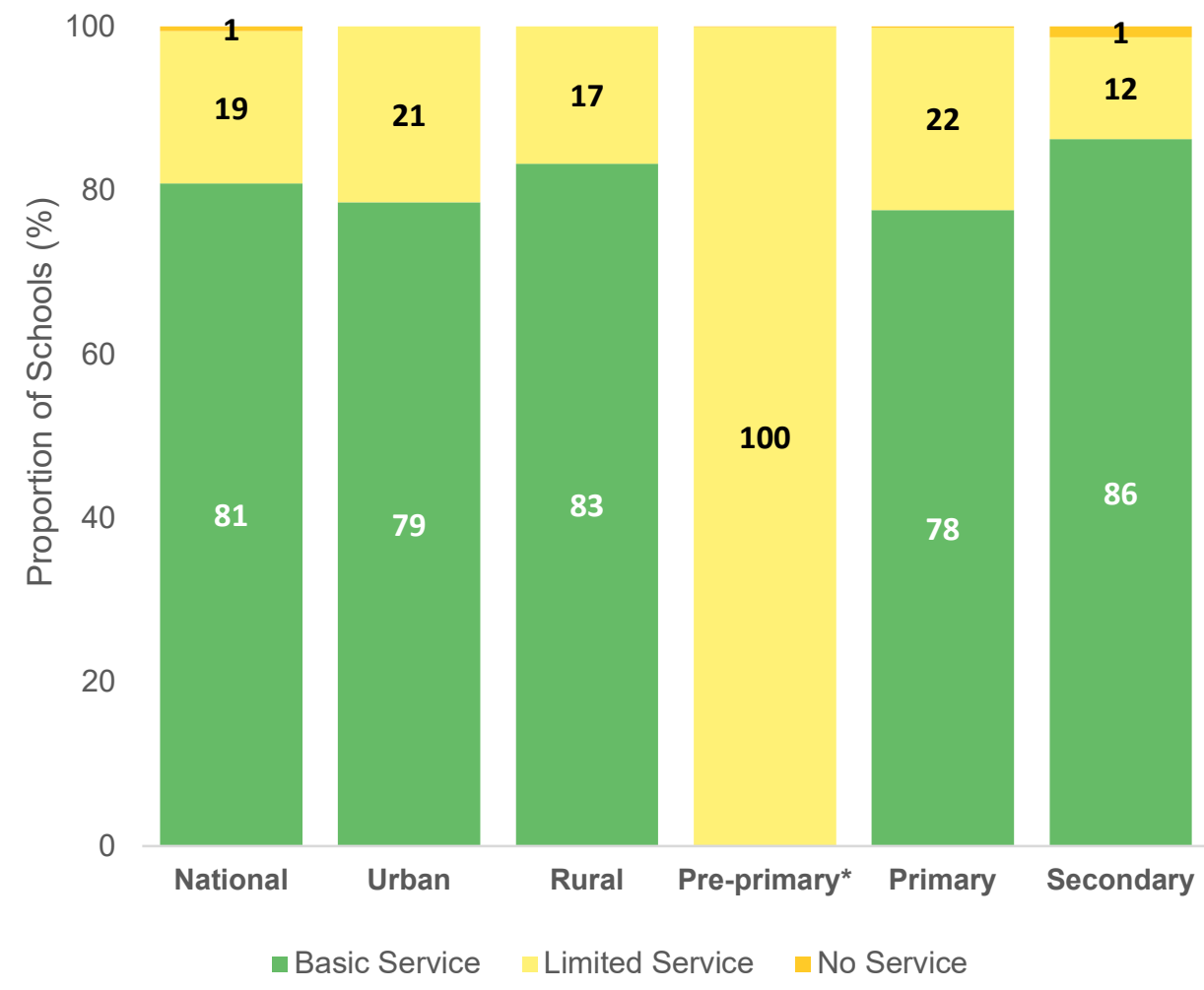

[CAP]Figure 2 Access to sanitation in schools

[S]Source: Joint Monitoring Programme (2018)

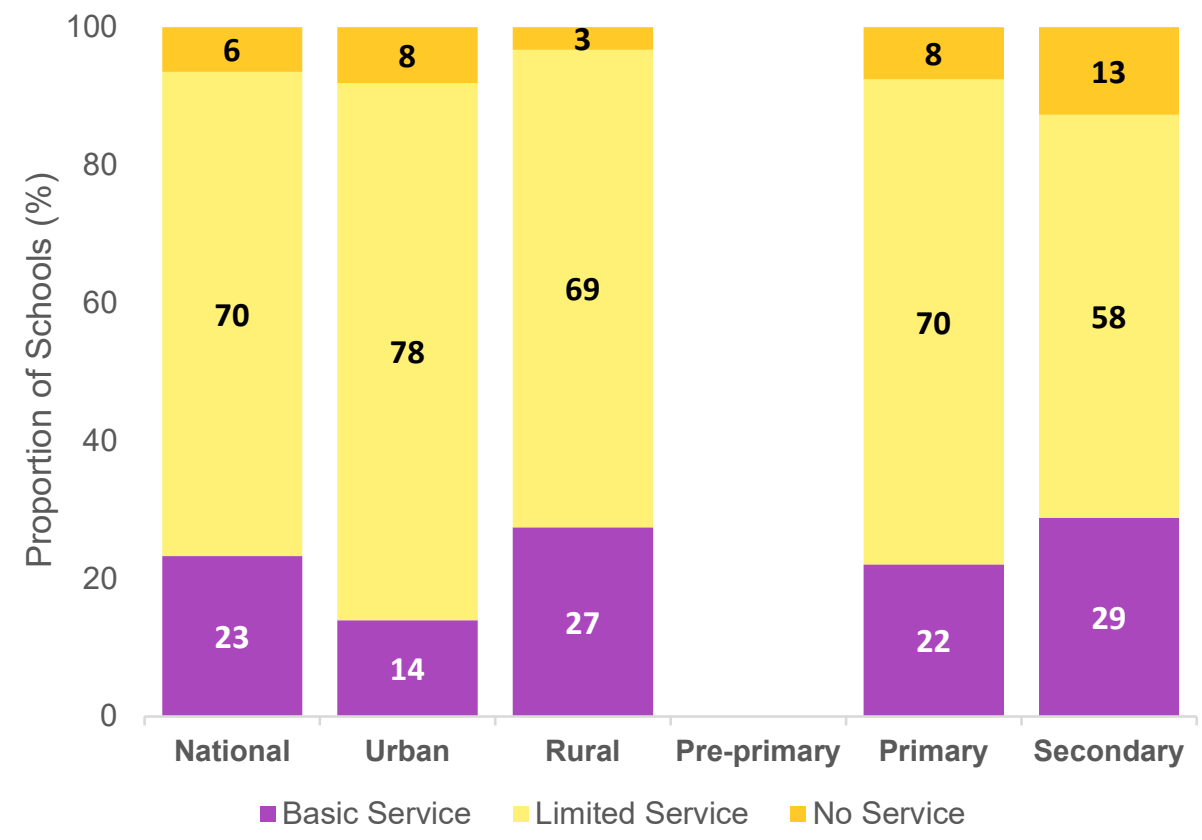

[CAP]Figure 3 Access to hygiene in schools

[S]Source: Joint Monitoring Programme (2018)

The Ministry of Education is the lead agency for implementation of WASH in schools programming, setting national standards of 40 pupils to one latrine/toilet/urinal, and 30 students to one wash basin. Seventy per cent of the schools meet these national standards (WASH in Schools Mapping, 2018). The government standard for provision of water (for drinking and hygiene) per pupil per day is 15 litres, with 80 per cent of schools meeting this (WASH in Schools Mapping, 2018). 
Hygiene kits (including a bar of hand soap, a toothbrush, a tube of toothpaste, and towels) have been distributed to first grade students (WASH in Schools, n.d.).

Many schools in the West Bank (particularly Area C) and Gaza suffer from drinking water shortages. Schools that are not connected to a water network rely on tankers and cisterns for their water supply, making storage capacity a critical issue for most schools.

MoEHE allocates funds to each school (approximately US\$2,000 per school) for WASH in schools programmes. Each school typically allocates 10-15 per cent of their budget for maintenance of the sanitation facilities, water supply, and hygiene promotionactivities. Schools have School Management Information Systems (SMIS) but these do not provide data on water and sanitation facilities in school.

\section{[A]Methods}

The paper is based on a desk based comparison of KAP surveys: the baseline survey (2012) and 2016 survey. The instruments used in the two KAP surveys included three questionnaires:

1. A questionnaire about the school: its grades; the number of students, teachers, staff, and cleaning personnel; the work of the hygiene committee; the condition of infrastructure; water availability and quality; toilet availability, quality, condition, and use; cleanliness; hygiene education; and washing facilities. The school questionnaire was administered to the school principal, sometimes in conjunction with a teacher responsible for WASH activities in the school.

2. Students' questionnaire that included questions about: knowledge of hygiene; sources of information on hygiene; use of toilets in the schools; opinions of the toilets' condition; and their hygiene practices. The data was collected in one-on-one interviews with students.

3. Teachers' questionnaire included questions on: school hygiene activities; teaching WASH topics in schools; teachers' perceptions of the school's cleanliness; and availability of WASH facilities. The data was collected in one-on-one interviews with teachers.

The 2016 survey also included three girls' focus groups on menstrual hygiene management, which was not addressed in the 2012 baseline survey.

Both the 2012 and 2016 KAP surveys covered all educational directorates in the West Bank (including Area C), East Jerusalem, and the Gaza Strip. School closures, transfers or changes in grade levels meant it was not possible to conduct the 2016 KAP survey in all the same schools as the 2012 survey. The 2016 sample included 381 of the original 411 sampled schools. The sample ensured the coverage of schools located in urban and rural areas, in addition to a few government-run schools located in camps. Out of the 381 schools surveyed, 257 were located in urban areas, 117 in rural areas and 7 in camps.

Respondents' anonymity and privacy was maintained in line with UNICEF Procedure for Ethical Standards. School-based data collection was organized to minimize disruptions to normal school life.

More detail on the primary data collection and data analysis is described in DFAT, UNICEF and Alpha International (2015-2016) Water, Sanitation and Hygiene in Schools: Knowledge, Attitudes and Practices Survey.

\section{[A]Findings}

This section compares the results of the 2016 KAP Survey on access to water with those from the 2012 baseline survey, in order to assess the degree and nature of change. The study's primary aim is to capture changes in WASH outcomes between two points in time (the survey published in 2012 reports on data collected in 2011 and the report published in 2016 reports on data collected in 2015). The study provides a snapshot of the situation and its evolution across time.

The 2012 baseline survey found that approximately 90 per cent of school principals believed the water supply at school was adequate or more than adequate for drinking, sanitation, personal hygiene, and cleaning purposes. However, the baseline survey also reflected various WASH problems, mainly related to the state of disrepair and lack of cleanliness of infrastructure (toilets, sinks or water fountains), their insufficient quantity, inadequate size, inadequate location, and the 
absence or lack of clean and safe drinking water. In 2016, more students had access to safe drinking water, sanitation facilities had been separated for girls and boys, and education provided for good hygiene.

\section{[B]Water sources}

Sources of water for the schools surveyed remained the same between 2012 and 2016. The main source of water for those in the West Bank was the public water network (93 per cent). In Gaza 84 per cent of the schools surveyed used water from tankers supplied by the MoEHE and UNICEF, private vendors, or humanitarian organizations. Schools in West Bank rural areas collected rainwater, which was used for all purposes. Water supplied from a source such as the water network in West Bank and water tankers in Gaza may not be safe for drinking.

\section{[B]Student to water point ratio}

MoEHE Guidelines for WASH in Schools recommend at least one water point for every 30 students. The student to water point ratio was higher in 2016 than in 2012, although there were significant variations between the West Bank and Gaza (49 students in the West Bank and 158 in Gaza; see Figure 4). The range across districts was also high (from 31 students per water point in Qalqilia to 204 in Rafah). Urban, boys' schools had the highest ratios. More than 90 per cent of the water points were observed to be safe and suitable for children in size, height, and faucet type.

\section{Student -to-water point ratio}

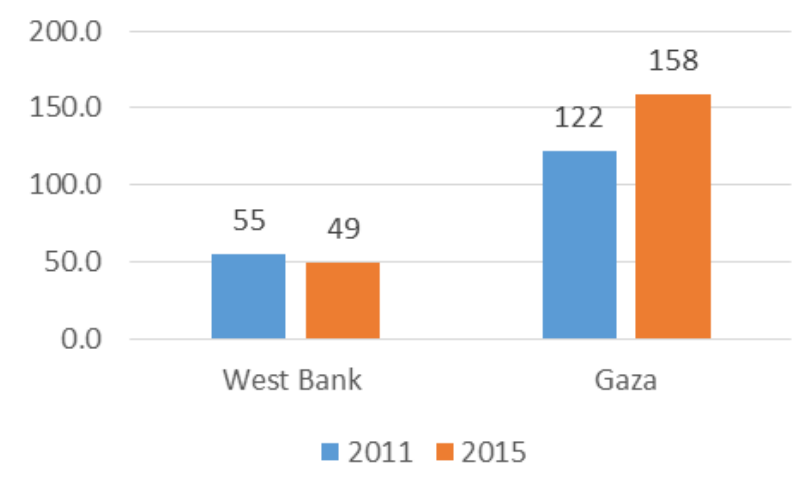

[CAP]Figure 4: Student to water point ratios

\section{[B]Availability of water for different purposes}

Water availability for all purposes improved in the study period (Figure 5). Only 13 per cent of principals reported not having water in the past two weeks compared with 20 per cent reporting the same in 2012; these figures were higher in Gaza (21 per cent) than in the West Bank (10 per cent). Similarly, the number of principals reporting a lack of water in the past six months had fallen ( 82 per cent in Gaza and 66 per cent in West Bank schools). Water availability for schools connected to the water network is known to be much higher during winter than summer. The lack of water during the previous two week and six month periods could be related to the season when the survey was conducted. 


\section{Water availability at schools for different purposes}

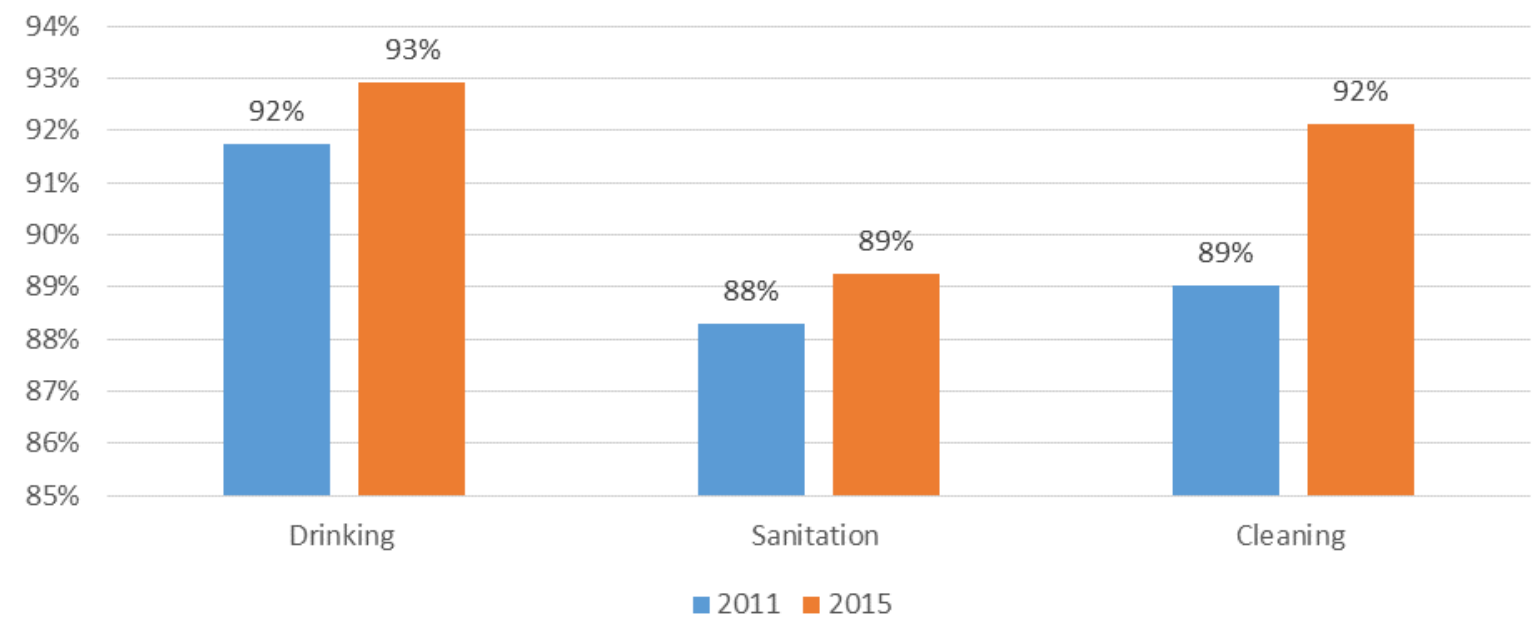

[CAP]Figure 5: Percentage of principals reporting water availability for different purposes in 2011 and 2015

\section{[B]Water storage}

As water supply in the SoP is intermittent, water storage tanks are important for the provision of adequate water for drinking and other purposes. About 92 per cent of schools in the West Bank reported having tanks at the schools that can store water for at least a week, compared with only 25 per cent of Gaza schools. Almost all the reported tanks were plastic (66 per cent), had wide openings (65 per cent), were well-covered (99 per cent), and clean (100 per cent). Additionally, 95 per cent of the schools reported cleaning these tanks from the inside by emptying and washing them once a semester ( 67 per cent) or once a year (25 per cent), with West Bank schools reporting more frequent cleaning than Gaza schools. More principals reported that tanks are washed from the inside compared with the baseline and the frequency of cleaning tanks once a semester also increased.

\section{[B]Water quality testing}

The Ministry of Health $(\mathrm{MoH})$ and the MoEHE are the agencies responsible for testing the water, with samples mostly collected by the MoH in the West Bank ( 79 per cent ), while in Gaza both the MoH and MoEHE collect samples for testing. More schools reported testing water in 2016 compared with the baseline. About 59 per cent reported that the water was tested once a year and 25 per cent once every six months. Seventy-six per cent of West Bank principals said that the water complied with standards set by the Palestinian Water Authority, while only 51 per cent of principals in Gaza reported the same. Forty-two per cent of principals in Gaza did not know the results of the water tests. If results were below standard, 69 per cent of the schools took action themselves to improve the water quality, rather than involving $\mathrm{MoH}, \mathrm{MoEHE}$ or the local authority.

\section{[B]Water treatment}

Water treatment in schools remained the same between 2012 and 2016. Although water for schools tends to be supplied from improved sources, the quality of the water cannot be guaranteed safe for drinking. Some schools treated their water prior to drinking (35 per cent of West Bank schools and 12 per cent in Gaza). Eighty-three per cent of schools in Gaza reported that they are not adequately equipped to treat water for safe drinking. Adding chlorine was the most common water treatment method reported by those schools ( 86 per cent) that treat water, followed by using a water filter ( 10 per cent), letting the water sit and settle (4 per cent), and boiling ( 1 per cent).

\section{[B]Hygiene}

The surveys also reveal several other WASH-related developments in Palestinian schools. Overall, surveyed schools in 2016 were generally cleaner compared with 2012. In 2016, all schools taught 
hygiene education to students and significantly more offer it on a daily basis. All surveyed schools had health committees and more schools had environment clubs in 2016, with increased student involvement. Teachers' participation in these and their role in providing hygiene education increased over the period, with fewer teachers reporting the need to be trained in hygiene-related topics. Parental participation in hygiene activities at the school did not change, however. The availability of resources for hygiene education was also better in 2016 than in 2012, with access to hygiene education information remaining high among students.

\section{[A]Discussion}

The availability and quality of water in schools in the study area has improved through construction and rehabilitation of drinking water points, water taps, and tanks as well as water tankering provision. Increased access to water in school has the potential to facilitate other hygiene practices such as toilet usage, hand-washing, and environmental cleanliness. Increased access to water supply also has the potential to support girls to manage menstruation using the school sanitation facilities provided. However, in the Gaza Strip, student to water point ratio had increased, possibly due to a combination of an increasing number of students served per school, destruction of school infrastructure, and/or inability to maintain the water points.

The survey findings indicate a number of areas for additional improvement. WASH infrastructure (toilets, handwashing facilities or drinking points) in Gaza were still a challenge in 2016. And although hygiene practices are reported to have improved, supplies of consumables are still inadequate in 2016 as a large percentage of schools did not have soap and toilet paper. Rate of refusal to use school toilets dropped between 2012 and 2016 but is still significant.

At the national level, MoEHE requires the financial resources to ensure sustained services. UNICEF estimates that rehabilitation and construction of WASH facilities would cost about $\$ 21 \mathrm{~m}$ in 680 of the most deprived schools, posing a significant financial burden on the affected schools. Principals must plan for WASH in their annual school budget, in line with the MoEHE's 2016 School Environment Policy. School personnel require financial management skills, together with an understanding of the lifecycle costs for water infrastructure in order to allocate sufficient funds. Donor support is therefore essential to further improve WASH infrastructure. Greater coordination in costsharing arrangements could be explored between communities, government, civil society organizations, and donors. With increased ownership of WASH services, parent-teacher associations, the school health committees, and the school environmental clubs have the potential to ensure sustained WASH provision in schools.

Increased water storage capacity is needed in schools in Gaza in particular (where an estimated 85 per cent lack sufficient storage capacity). In addition, not all schools have their water tested; West Bank schools are more likely to have water testing for all chemical, biological, and physical parameters than schools in Gaza. Many schools in Gaza rely on drinking water bought from tankers, which is expensive and may not be safe to drink. Roles and responsibilities as well as accountabilities for making sure school drinking water meets quality standards are unclear, with water quality mainly overseen by the school administration. National standards for water quality and corrective action have yet to be clearly defined. Better communication and application of MoEHE's 2015 school environment policy and 2013 guidelines is also necessary (MoEHE, 2003).

Recognizing that the context places some limitations on the ability of authorities to undertake all recommendations, the study calls for the following:

- Standardization of water quality management across all government schools and communication of guidelines and instructions to the school administration.

- In Gaza, continue to improve the availability of toilets, handwashing facilities, water storage tanks, and drinking faucets in schools.

- If water quality testing results do not meet national standards, guidelines for corrective action need to be communicated to the school administration.

- Maintain a management information system (EMIS) in MoEHE.

- Enhance parental and student participation in WASH-related activities at schools.

- Ensure operation and maintenance standards for WASH facilities are implemented in schools. 
- Maintain students' high level of hygiene knowledge and ensure this leads to practice of improved behaviours.

\section{[A]Limitations}

The study had a number of limitations. The questionnaire was described as being long. However, the research team did not reduce the length as this would have affected the comparison with the 2012 baseline survey. The younger grades (mainly fourth) reported finding it very difficult to recall the activities and the knowledge they gained over the past six months, as there were very few activities during this time, which included the end of the previous year, the summer vacation, and the beginning of the academic year. In a few cases, students had clearly not understood the term 'water treatment'. This meant that in the actual data collection, the data collectors should have ensured that the students understood water treatment before seeking a response. The paper presents data as percentage of schools over the total number of surveyed schools rather than the number of served/affected students. It is noted that urban schools in the Gaza Strip might serve over 1,000 students, unlike rural schools in the West Bank, which can serve as few as 50 students.

\section{[A]Conclusion}

Despite continued challenges related to the context, water access improved overall in Palestinian schools in the period 2012 to 2016, with increased water availability for all purposes and more schools testing the quality of water. However, there is room for further improvement on water storage and water quality.

\section{[A]References}

Alexander, K.T., Mwaki, A., Adhiambo, D., Cheney-Coker, M., Muga, R., and Freeman, M.C. (2016)

'The life-cycle costs of school water, sanitation and hygiene access in Kenyan primary schools', International Journal of Environmental Research and Public Health 13(7): 637

$<$ http://dx.doi.org/10.3390/ijerph13070637>.

Al-Khatib, Issam A., Abusara, L.W., Odeh, Y.M., Sbeih, S.A., and Massoud, M.A. (2015) 'Hand washing among Palestinians in the West Bank and Gaza Strip: attitudes and practices', Journal of Environmental Health 77(6): 50-7.

Chard, A.N., and Freeman, M.C. (2018) 'Design, intervention fidelity, and behavioral outcomes of a school-based water, sanitation, and hygiene cluster-randomized trial in Laos', International Journal of Environmental Research and Public Health 15(4): 570

$<$ http://dx.doi.org/10.3390/ijerph15040570>

Dreibelbis, R., Freeman, M.C., Greene, L.E., Saboori, S., and Rheingans, R. (2014) 'The impact of school water, sanitation, and hygiene interventions on the health of younger siblings of pupils: a cluster-randomized trial in Kenya', American Journal of Public Health 104(1): e91-7 $<$ http://dx.doi.org/10.2105/AJPH.2013.301412>.

Freeman, M.C., Strunz, E., Utzinger, J., and Addiss, D.G. (2016) 'Interventions to improve water, sanitation, and hygiene for preventing soil-transmitted helminth infection', Cochrane Database of Systematic Reviews 5: CD012199 <http://dx.doi.org/10.1002/14651858.CD012199>. 
Garn, J.V., Greene, L.E., Dreibelbis, R., Saboori, S., Rheingans, R.D., and Freeman, M.C. (2013) ‘A cluster-randomized trial assessing the impact of school water, sanitation, and hygiene improvements on pupil enrollment and gender parity in enrollment', Journal of Water, Sanitation and Hygiene for Development 3(4): 592-601 <http://dx.doi.org/10.2166/washdev.2013.217>.

Garn, J.V., Brumback, B.A., Drews-Botsch, C.D., Lash, T.L., Kramer, M.R., Freeman, M.C. (2016) 'Estimating the effect of school water, sanitation, and hygiene improvements on pupil health outcomes', Epidemiology 27(5): 752-60 <http://dx.doi.org/10.1097/EDE.0000000000000522>.

Ghrayeb Farid, A.W., Rusli, A.M., Al Rifai, A., and Ismail, I.M. (2015) 'Hand-washing behavior and hygiene-related facilities among school adolescents in Palestine', Indian Journal of Public Health Research and Development 6(3) <http://dx.doi.org/10.5958/0976-5506.2015.00132.1>.

Grimes, J.E., Tadesse, G., Mekete, K., Wuletaw, Y., Gebretsadik, A., French, M.D., Harrison, W.E., Drake, L.J., Gardiner, I.A., Yard, E., and Templeton, M.R. (2016) 'School water, sanitation, and hygiene, soil-transmitted helminths, and schistosomes: national mapping in Ethiopia', PLoS Neglected Tropical Diseases 10(3): e0004515 <http://dx.doi.org/10.1371/journal.pntd.0004515>. GVC, UN Women, Palestinian Water Authority and AICS - Agenzia Italiana per la Cooperazione allo Sviluppo (2017) Gender Equality and Water, Sanitation and Hygiene in Palestine, Bologna: GVC.

Hunter, P.R., Risebro, H., Yen, M., Lefebvre, H., Lo, C., Hartemann, P., Longuet, C., and Jaquenoud, F. (2015) 'Impact of the provision of safe drinking water on school absence rates in Cambodia: a quasi-experimental study', Annals of Nutrition \& Metabolism 66(Suppl 3): 31-7 $<$ http://dx.doi.org/10.1159/000381244>.

MoEHE (2003) Guidebook of School Health and Environment Standards, Palestinian National Committee of School Health and Environment Standards, School Health National Committee. Trinies, V., Garn, J., Chan, H.H., and Freeman, M.C. (2016) 'The impact of a comprehensive school WASH program on absenteeism, diarrhea, and respiratory infection symptoms: a matched-control trial in Mali', American Journal of Tropical Medicine and Hygiene 94: 1418-25.

UNICEF and Ministry of Education, State of Palestine (2016) Water, Sanitation and Hygiene in Schools: Knowledge, Attitudes and Practices Survey [pdf], Government of Australia (DFAT), Ministry of Education and Higher Education, the United Nations Children's Fund (UNICEF) office in the State of Palestine, and Alpha International $<$ https://www.unicef.org/oPt/Water_Sanitation_Survey.pdf $>$ [accessed 13 February 2019].

WASH in Schools (no date) 'Mapping: Palestine' [online]

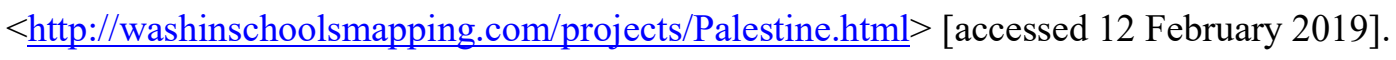


G. VON MEDEAZZA et al.

ACCESS TO WASH IN PALESTINIAN SCHOOLS

WHO/UNICEF Joint Monitoring Programme (2018) Drinking Water, Sanitation and Hygiene in Schools: Global Baseline Report 2018 [pdf], WHO/UNICEF Joint Monitoring Programme for Water Supply, Sanitation and Hygiene $<$ https://washdata.org/sites/default/files/documents/reports/201811/JMP\%20WASH\%20in\%20Schools\%20WEB\%20final.pdf $>$ [accessed 12 February 2019]. 